Food and Nutrition Report

\title{
Relationships between Home Environment Factors and Parental Report of Diet Quality, Physical Activity and Sedentary Behaviours in 4-5 year olds: A Cross-sectional Study
}

\author{
Anthea Magarey PhD, Eva Leslie PhD* and Julie Tan BND (Hons) \\ Department of Nutrition and Dietetics, School of Health Sciences, Flinders University, Bedford Park, South Australia 5042, Australia
}

\begin{abstract}
*Corresponding Author: Eva R Leslie, PhD, Senior Research Fellow, Nutrition and Dietetics, School of Health Sciences, Faculty of Medicine, Nursing and Health Sciences, Flinders University, GPO Box 2100, Adelaide SA 5001, Australia, Tel: +61-8-8204-6303, Fax: +61-8-8204-6406; Email: evie.leslie@flinders.edu.au
\end{abstract}

Article Type: Research, Submission Date: 29 May 2015, Accepted Date: 17 June 2015, Published Date: 25 June 2015.

Citation: Anthea Magarey PhD, Eva Leslie PhD and Julie Tan BND (Hons) (2015) Relationships between Home Environment Factors and Parental Report of Diet Quality, Physical Activity and Sedentary Behaviours in 4-5 year olds: A Cross-sectional Study. F Nutr Reprt 1(1): 9-15. doi: https://doi.org/10.24218/fnr.2015.02.

Copyright: (c) 2015 Eva R Leslie. This is an open-access article distributed under the terms of the Creative Commons Attribution License, which permits unrestricted use, distribution, and reproduction in any medium, provided the original author and source are credited.

\section{Abstract}

Objective: This study assessed home environment (HE) factors associated with diet quality and meeting physical activity (PA) and sedentary behaviour (SB) National Guidelines among a sample of pre-school children.

Design: Analysis of cross sectional baseline data of a communitybased study collected 2011-13.

Setting: Twenty geographically bounded metropolitan/regional South Australian communities.

Participants: Parents $(\mathrm{n}=1790)$ of children aged $4-5$ years from participating pre-schools in selected communities.

Variables measured: Parent-reported child food intake (fruit, vegetables, milk, non-core foods), eating behaviours, home environment factors (parental knowledge/ modelling, family practices, and availability of equipment /electronic media).

Analysis: Linear regression model examined child diet quality and home environment. Logistic regression examined associations between HE and meeting PA and SB guidelines.

Results: HE was a significant predictor of child dietary score, with a higher (more health promoting) score positively associated with an increased healthy diet score $(\beta=0.44 ; p<0.001)$. Children whose parents had a university degree, knew recommendations and were active were more likely to meet PA guidelines. Children whose parents knew the recommendations, were active and in homes where the TV was not left on frequently/all the time were more likely to meet SB guidelines.

Conclusions and Implications: Targeting HE factors through family-based interventions may help improve lifestyle behaviours for pre-schoolers.

Keywords: Family environment, Obesogenic behaviours, Dietary patterns, Recommendations

\section{Introduction}

Obesity is one of the greatest health challenges of the $21^{\text {st }}$ century
[1]. One in five children as young as five years old is overweight or obese in Australia [2,3] and, obese children are likely to become obese adults [4]. While usually not a clinical problem, overweight is a major risk factor for many chronic lifestyle diseases [5]. The detrimental effects to health, social well-being, and accompanying high health costs for individuals and society makes it one of the priority health problems to prevent.

Swinburn's Ecological Model of Obesity proposes that environmental factors influence behaviours, thereby indirectly affecting energy balance [6]. Studies support the notion that obesity arises from weight gain promoting behaviours, collectively coined obesogenic behaviours, of low physical activity, high sedentary behaviour and high-energy intake $[7,8]$. Since characteristics of the environment underlie the formation of these behaviours [6], it is important to identify potentially modifiable aspects of children's environments as possible targets for intervention. Children are broadly defined as being between 0-12 years old; however, they cannot be considered a homogeneous group due to different developmental stages that occur over this period. Studies investigating obesity that are inclusive of both preschoolers (4-5 years) and primary school children (6-12 years) limits any conclusions that can be made about specific factors influencing obesity in preschoolers.

Despite their attendance at either preschool or day care centres, the family home largely shapes the development of behavioural patterns for children aged 4-5 years [9-11]. Parents as primary carers and decision makers act as 'gatekeepers' of the family home and create the food and activity environment for their children, who in turn imitate their parents' behaviours and learn through parental encouragement and reinforcement [12]. While specific individual aspects of the home environment are of interest in relation to influences on obesogenic behaviours, the home environment is complex and it is conceptually possible for positive factors to negate negative factors. Thus it is important to study the overall home environment, as well as individual aspects of the environment, to gain a better understanding of home influences that are largely shaped by parents' characteristics. 
Given the complexity of the human diet an overall assessment of diet quality is warranted, while at the same time, it is relevant to assess the association between the overall home environment and whether or not children meet physical activity and sedentary behaviour recommendations [13].

Thus the aim of this study was to investigate the relationship between home environment factors (parent knowledge, attitudes, modelling, rules, availability, and physical environment) and the diet quality, physical activity and sedentary behaviours of children aged $4-5$ years.

\section{Methods}

\section{Participants and Recruitment}

This study uses baseline evaluation data from the Obesity Prevention and Lifestyle (OPAL) Project. OPAL is a statefunded, multi-site, community-based obesity prevention program implemented in twenty local government areas across metropolitan and rural South Australia (SA), based on EPODE (Ensemble, Prévenons l'Obésité Des Enfants) methodology [14]. The aim of OPAL is to increase the proportion of children aged 0 -18 years in the healthy weight range, as defined by International Obesity Task Force cut-points [15]. This study focuses on crosssectional baseline survey data from parents of preschool children aged $4-5$ years.

Data were collected between November 2011 and August 2013. Twenty communities were sequentially enrolled in four phases into the OPAL program. The communities were selected based on a product developed by the Australian Bureau of Statistics that ranks areas in Australia according to relative social advantage and disadvantage, called the Socio-Economic Index for Areas (SEIFA) index, maternal education and child population and community readiness for participation. Control communities were matched as closely as possible to each intervention community on the basis of maternal education, geographical location (metropolitan vs. rural), Index of Relative Social Disadvantage(IRSD) (a component of SEIFA based on a basket of income- and education-related measures), and population of 0-18 year olds. All preschools and day care centres within these communities were identified. Recruitment to the study involved the mailing of an information pack to all centre directors/principals followed by a telephone call, inviting them to participate. Parent information packs provided by the evaluation team were distributed to parents/guardians of 4-5 year olds attending preschools/centres by staff at consenting preschools/centres, inviting them to complete the enclosed questionnaire which included items on socio-demographics, the home environment and the physical activity, sedentary behaviour and eating behaviours of their 4-5 year old children. Completed questionnaires were returned to the preschools or centres via the child. The study protocol was approved by Flinders University Social and Behavioural Research Ethics Committee and other relevant human research ethics committees.

\section{Measures}

The parent questionnaire was specifically developed by OPAL to provide process and impact evaluation of the intervention, using previously validated items. This analysis uses a subset of questions from the questionnaire, described below.

Socio-demographic data: Demographics were collected via the questionnaire. Child gender, country of birth categorised as whether Australian born (yes/no), main language spoke at home categorised as English (yes/no), respondent's gender, indigenous status (yes/no) and education level reported as the highest of seven categories and collapsed into three, school only, postschool trade/certificate, and university degree, household annual income reported across 10 categories and collapsed into three; up to $\$ 35,000, \$ 35,001$ to $\$ 70,000$, and greater than $\$ 70,000$. Area of residence was categorised as metropolitan or regional based on the location of the preschool their child attended.

Child healthy diet score: To assess diet quality, a healthy diet score was constructed from available caregiver reported dietary items which included intake of fruit, vegetable, milk, and a range of non-core foods [7] (those foods and beverages that are surplus to the requirements of a healthy diet and which are typically high energy/fat/sugar/salt foods), and several behaviours associated with poor diet quality. A total of eight items was used. Answers to the questions how frequently does your child eat fruit/ vegetables were assigned a score of 0 if never or no more than 3-4 times a week, 1 for 5-6 times or about once a day, and 2 for two or more times a day. Responses to did your child eat potato (excluding fried potato)/other vegetables and legumes yesterday and if yes how many serves (where serves were defined as per the Australian Guide to Healthy Eating (AGHE) [16] were used to determine serves of vegetable on the previous day. Serves of fruit consumed the previous day were similarly estimated. A score was allocated for intake of each of fruit and vegetables based on adherence to meeting AGHE recommendations ( $0=$ ate no fruit/ vegetable, $1=$ ate some but insufficient, $2=$ met recommendations) using cut-points of two serves of fruit and three of vegetables. While the guidelines stipulate 1-2 serves for fruit, the higher value was used as it is known that parents tend to overestimate intake when assessing the number of serves [17]. The Dietary guidelines (15) recommend children above two years of age use reduced fat milk and use of reduced fat milk is a key strategy supporting energy balance [18]. Usual type of milk consumed was scored as 2 for low or reduced fat milk, 1 for full cream milk, flavoured milk, evaporated milk or condensed milk and $0=$ did not drink any milk. Caregivers reported their child's intake the previous day of five food groups; sugar sweetened soft drinks and cordials, fruit juices and fruit drinks, savoury and/or salty snacks, lollies chocolate and fruit bars, cakes doughnuts sweet biscuits muffins and muesli bars, and ice cream icy poles and ice blocks, as typical serves relevant for each item. Intake was converted to non-core food serves based on a serve equating to $600 \mathrm{~kJ}$ and total serves scored as $0=$ ate more than two serves, $1=$ ate up to two serves, and $2=$ did not eat any of the non-core foods/beverages. Behaviour items were number of days child usually consumed breakfast scored as $0=0-4$ times/week, $1=5-6$ times/week, $2=$ every day, and number of times in a week child usually ate fast food or takeaway scored as $2=$ no days, $1=$ once or twice a week and $0=$ three or more times a week. Individual scores were summed to give a continuous score (range 0-16) where higher scores represent a more desirable dietary pattern.

Child physical activity: One item in the questionnaire 'amount of time spent outside on the last day your child was at preschool' assessed physical activity. Responses were open ended and collapsed into two categories, meeting physical activity guidelines for preschoolers (3-5 years) of being moderately active for at least three hours per day or not meeting the guideline, where being 
Citation: Anthea Magarey PhD, Eva Leslie PhD and Julie Tan BND (Hons) (2015) Relationships between Home Environment Factors and Parental Report of Diet Quality, Physical Activity and Sedentary Behaviours in 4-5 year olds: A Cross-sectional Study. F Nutr Reprt 1(1): 9-15. doi: https:// doi.org/10.24218/fnr.2015.02.

outside was assumed to be time spent moderately active [13].

Child sedentary behaviour: Screen time (time spent using electronic media) was used to assess child's sedentary behaviour. Total screen time per day was estimated by summing two items; time spent watching TV/videos/DVD and time spent playing computer or video games the previous day, outside of preschool hours. Responses were dichotomised into meeting the recommendations to limit the time spent being sedentary for children (0-5 years) for no more than 1 hour/day, or not meeting the recommendation [13].

Home environment factors influencing dietary behaviour: A healthy home food environment score was created from 16 items. Parental knowledge of recommended serves of fruit and of vegetables per day for 4-5 year olds was dichotomised to 'correct' (score 1) (2 serves of fruit, 3 serves of vegetable) or 'incorrect' (score 0 ). Respondent reported usual intake of fruit and vegetables was used to assess modelling and scored 0 for not consuming, 1 for consuming some but less than recommended ( 2 serves of fruit, 5 serves of vegetables) and 2 for consuming the recommended serves or more. Seven food related behaviours were assessed on a 5-point Likert scale collapsed to three for scoring $(0=$ never/rarely, $1=$ sometimes, $2=$ often/always). The items were eating food I want my child to eat, an adult in the house cooks an evening meal, child helps prepare food, caregiver encourages child to eat fruit, caregiver encourages child to eat vegetables, vegetables are served at dinner and caregiver sits with child at mealtimes. A further three items were similarly assessed but reverse scored $(2=$ never/rarely, $1=$ sometimes, $0=$ often/ always). These were food is used as a reward for good behaviour, food is withheld as punishment for bad behaviour and child is allowed to eat snacks and /or sweets without permission. Number of days a week the primary and/or secondary caregiver eats the main meal of the day with the child and number of days in the last week the child watched TV while eating their evening meal were open-ended and scored as $0=$ none or 1 day, $1=2$ to 4 days and $2=$ five or more days, and $0=$ no days, $1=1$ to 3 days and $2=4$ to 7 days, respectively. Individual scores were summed to give a continuous score (range 0-30) where a higher score represents a healthier home food environment.

Home environment factors influencing physical activity: Four items were used. Caregiver knowledge of physical activity recommendations (1 item) was assessed against the National Physical Activity Guidelines [13] and dichotomised to 'correct' ( $\geq 3$ hours/day) and 'incorrect' ( $<3$ hours/day). Responses more than the actual recommendations were considered correct. Caregiver role modelling ( 2 items) was assessed as the frequency that the primary and secondary caregivers participated in $\geq 30$ minutes of physical activity in a week and collapsed into three categories (0-2 times/week, 3-4 times/week, 5-7 times/week). Home availability of equipment related to physical activity (1 item) was determined as the total number of eleven items available at home. Responses for each item were obtained on a 6 point frequency scale of usage by the child and dichotomised to 'available' and 'unavailable'.

Home environment factors influencing sedentary behaviour: Nine items were used. Caregiver knowledge of recommendations (1 item) for the time a child should watch TV/videos/DVDs or play computer or electronic games was assessed against the
National Physical Activity Guidelines for children 2 to 5 years [13] and dichotomised into 'correct' (1 hour or less/day) or 'incorrect' ( $>1$ hour/day). Caregiver role modelling (2 items) for sedentary behaviour was assessed as the amount of time the primary and secondary caregivers spent watching TV per day and dichotomised into meeting recommendations (2 hours or less) or not meeting recommendations ( $>2$ hours). Home availability of equipment (3 items) covered the number of TVs, computers (desktops, laptops, iPads) and video game consoles (Xbox, PlayStation excluding Wii) in the household. Presence of a TV in the child's bedroom was a 'yes/no' question. Another item asked about the TV being left on even when no one was watching and answered on a 5 point frequency scale with responses collapsed into three categories ( $0=$ 'all the time/frequently', $1=$ 'sometimes/ occasionally', 2 ='never'). Caregivers were also asked if they set rules on children's usage of TV, video games or computer (1 item) with responses categorised as $0=$ not at all/somewhat, $1=\mathrm{a}$ little, and $2=$ a lot.

Data analysis: Statistical analyses were conducted using SPSS version 19.0 (Windows, Chicago, IL, USA). Categorical data are presented as frequencies and continuous data as means (sd) or median (interquartile range) as appropriate. The healthy home food environment score and identified covariates (child gender, respondent's education level, household income and area of residence) were entered into a linear regression model with the dietary score as the outcome variable. Assumptions of multicollinearity, outliers and homoscedasticity of residuals were checked. Standardised regression coefficients $(\beta)$ and $95 \%$ confidence intervals assessed the strength of the relationship found. Logistic regression was used to explore the relationship between home environment factors and whether the recommendations for physical activity and small screen time were met. An initial univariate analysis was conducted between each predictor variable and child outcome followed by a multivariate model where all identified predictor variables and covariates were added in the one model. Indigenous status and main language spoken at home were not entered as covariates because of low prevalence in this population $(1.1 \%$ and $3.6 \%$ respectively). Results are expressed as odds ratio and 95\% CI with level of significance set at $p<0.05$.

\section{Results}

A total of 1790 caregivers provided survey data. A majority of respondents were female (94.7\%), the primary caregiver (96.5\%), the biological parent (96.4\%), born in Australia (95.2\%) and nonindigenous (98.2\%). A quarter (27.1\%) had a school education only, $34.1 \%$ trade or certificate qualification and $38.7 \%$ a university degree. English was the main language spoken at home (96.2\%), more than half $(52.3 \%)$ had an annual gross household income greater than $\$ 70000(936 / 1598)$ and a majority lived in the metropolitan area $(65.8 \%)$. Child age could not be computed due to missing information on date of questionnaire completion but as they were all recruited from preschools and day care centres; they were within the range of 4-5 years old. About half (52.6\%) the children were male.

Complete data to calculate both the healthy home environment score and healthy diet score were available for 1490 cases. Due to missing data for covariates (principally level of income) the number of cases in the regression analysis was 1410. There were 
Citation: Anthea Magarey PhD, Eva Leslie PhD and Julie Tan BND (Hons) (2015) Relationships between Home Environment Factors and Parental Report of Diet Quality, Physical Activity and Sedentary Behaviours in 4-5 year olds: A Cross-sectional Study. F Nutr Reprt 1(1): 9-15. doi: https:// doi.org/10.24218/fnr.2015.02.

no differences for respondent education or area of residence between those included in the analysis and the full sample but a greater proportion of the former had an income above $\$ 70,000$ (59.6 v 52.3\%). The mean (SD) healthy home food environment score was 24.7 (2.2) with a range of 12 to 29 and the mean (SD) healthy diet score was 10.4 (2.1) with a range of 2 to 16 . The multiple linear regression analysis presented in Table 1 shows that after adjusting for demographic factors, a higher (more health promoting) healthy home food environment score was positively associated with an increased healthy diet score $(\Omega=0.44 ; p<0.001)$. Child gender, household income and caregiver education made small significant contributions to the variance, $24.4 \%$ of which was explained by the model.

Table 1: Results of multiple linear regression analysis: healthy home food environment score and child healthy diet score (adjusted for covariates)

\begin{tabular}{|l|l|l|l|}
\hline & \multicolumn{3}{|l|}{ Healthy diet score $^{\mathrm{ab}}(\mathbf{n = 1 4 1 0})$} \\
\hline & Unstandardised B & $\mathbf{B}$ & $\mathbf{p}$-value \\
\hline Covariates & $\mathbf{9 5 \%} \mathrm{Cl})$ & & \\
\hline Child gender & & & \\
\hline Education & $0.29(0.09,0.49)$ & 0.07 & 0.005 \\
\hline Income & $0.34(0.20,0.47)$ & 0.12 & $<0.001$ \\
\hline Area & $0.27(0.12,0.41)$ & 0.09 & $<0.001$ \\
\hline Predictor & $-0.11(-0.35,0.08)$ & -0.02 & 0.30 \\
\hline Healthy environment score & $0.43(0.38,0.47)$ & 0.44 & $<0.001$ \\
\hline$R^{2}$ & 0.244 & & \\
\hline
\end{tabular}

${ }^{a}$ Healthy diet score calculated from 8 items describing child dietary intake (see methods for detail).

${ }^{\mathrm{b}}$ Adjusted for covariates (child gender, parent education level, income level and metropolitan/regional area of residence)

' Healthy home food environment score calculated from 16 items describing the home environment (see methods for detail) based on parental knowledge, behaviours and rules. If one or more items within a score were missing, that score was not calculated, resulting in 367 missing cases.

Table 2 presents the results of the logistic regression investigating the relationship between home environment factors relevant to physical activity and whether the child had been outside for at least 3 hours on the last day at preschool, and the home environment factors relevant to sedentary behavior and whether the child had spent no more than one hour on screen use the previous day. Data were available for 1015 and 1345 cases respectively to investigate these relationships. Compared with the full sample a greater proportion in the former sample had a university education ( $38.7 \%$ versus $45 \%)$ and an income greater than $\$ 70,000$ (58.6\% versus $66.9 \%$ ). Differences between the full sample and the sample for sedentary behaviour were less than four percent in these factors. Only $34.9 \%(n=354 / 1015)$ of children met the recommendations of being active more than three hours on their last day at preschool. Children of respondents who knew the physical activity guidelines, had a university degree, and whose primary caregiver was active for 30 minutes five or more times a week were more likely to have spent at least three hours outside on the last day they were at preschool. However the model described only 4.2 to $5.8 \%$ of the variance in whether or not recommendations were met. About one-third ( $n=505 / 1345$, $37.5 \%$ ) of children met recommendations of no more than $1 \mathrm{hr}$ of screen time the previous day. Children of respondents who knew the recommendations for limiting sedentary behaviour, whose primary caregiver was active for 30 minutes or more at least five times a week, and in homes where the TV was not left on frequently or all the time were more likely to meet sedentary behaviour recommendations (i.e. no more than 1 hour of screen time the previous day). Overall the model explained only 9.6 to $13.1 \%$ of the variance.

\section{Discussion}

This study investigated the relationship between the home environment and preschoolers' diet quality, physical activity and sedentary behaviours. We found a significant relationship between the home environment and each of these behaviours, such that a healthier home food environment (i.e. one more supportive of the desired behaviour) was associated with a healthier food intake, and with a greater likelihood of a child meeting physical activity and sedentary behaviour (screen time) guidelines. While almost $25 \%$ of variance in the dietary intake score was explained by the home environment factors that influence dietary behaviour, less than $6 \%$ of variance in whether physical activity guidelines were met or not, and less than $15 \%$ of variance in meeting sedentary behaviour guidelines or not were explained by the respective home environment factors influencing these behaviours.

This study is unique in generating a composite measure to score the home food environment encompassing parent diet intake, modelling, attitudes, knowledge and parenting behaviours, and a composite measure of dietary behaviour incorporating intake of a number of food groups and behaviours. Importantly, this includes assessment of non-core foods, which have been found to be consumed in excess by Australian children [7]. Several previous studies report the relationship between the home food environment and dietary intake in young children [19-21]. Direct comparisons of our findings with these studies is difficult as two studies $[19,20]$ considered each dietary behaviour separately rather than a composite score, as in the present study, while the third combined both fruit and vegetables [21]. Additionally child intake of the food items of interest was assessed in diverse ways. The environmental variables in these studies were varied and included as individual independent items rather than as a single composite home environment item. Despite these differences our results support previous findings of the link between home environment and child dietary intake. The variance described by our model $(25 \%)$ is within the range reported by these previous studies of 7 to $20 \%$ for savoury snack, sweets snack, sweet beverages and vegetable consumption [20], 21 to $44 \%$ noncore foods, drinks, fruits and vegetables [19], 48\% for fruit and vegetables [21]. The greater variance in the last two studies may be accounted for in part by inclusion of children's liking for a food [19] and food accessibility and availability [21]. Our results confirm the role of the home food environment in predicting dietary intake for 4-5 year old children and support the potential of targeting the multiple factors in the home eating environment to improve the quality of their dietary intake.

Time spent outdoors was used to represent outdoor physical activity for this age group and was positively associated with 
Citation: Anthea Magarey PhD, Eva Leslie PhD and Julie Tan BND (Hons) (2015) Relationships between Home Environment Factors and Parental Report of Diet Quality, Physical Activity and Sedentary Behaviours in 4-5 year olds: A Cross-sectional Study. F Nutr Reprt 1(1): 9-15. doi: https:// doi.org/10.24218/fnr.2015.02.

Table 2: Multivariate associations between socio-demographic and home environment factors and pre-schoolers meeting physical activity ( $\mathrm{N}=$ 1015 ) and sedentary behaviour ( $N=1354)$ guidelines.

\begin{tabular}{|c|c|c|c|c|c|}
\hline \multirow[t]{2}{*}{ Predictor } & & \multicolumn{2}{|c|}{$\begin{array}{l}\text { Meets physical activity guidelines }{ }^{a} \\
(\mathrm{n}=354)\end{array}$} & \multicolumn{2}{|c|}{$\begin{array}{l}\text { Meets sedentary behaviour guidelines }{ }^{b} \\
\qquad(n=505)\end{array}$} \\
\hline & & $\mathrm{n}$ & OR $(95 \% \mathrm{Cl})^{c}$ & $\mathrm{n}$ & OR $(95 \% \mathrm{Cl})$ \\
\hline \multicolumn{6}{|l|}{ SD factors } \\
\hline \multirow[t]{2}{*}{ Child gender } & Boy & 533 & ref & & \\
\hline & Girl & 482 & $0.83[0.63,1.08]$ & & $1.23[0.97,1.55]$ \\
\hline \multirow[t]{3}{*}{ Education level } & School only & 219 & ref & 321 & ref \\
\hline & Trade $^{d}$ & 338 & $1.16[0.79,1.69]$ & 448 & $0.96[0.69,1.32]$ \\
\hline & Uni degree & 458 & $1.46[1.01,2.11]^{*}$ & 576 & $1.01[0.73,1.40]$ \\
\hline \multirow[t]{3}{*}{ Income level } & $\$ 0$ to $\$ 35000$ & 60 & ref & 82 & Ref \\
\hline & $\$ 35001$ to $\$ 70000$ & 276 & $1.41[0.72,2.74]$ & 377 & $1.05[0.61,1.80]$ \\
\hline & $\geq \$ 70001$ & 679 & $1.65[0.87,3.13]$ & 886 & $1.40[0.83,2.37]$ \\
\hline \multirow[t]{2}{*}{ Area } & Metro & 677 & ref & 880 & ref \\
\hline & Regional & 338 & $1.07[0.81,1.43]$ & 465 & $1.06[0.83,1.36]$ \\
\hline \multicolumn{6}{|c|}{ Home environment factors } \\
\hline \multirow[t]{2}{*}{ Knowledge } & Recs unknown & 719 & ref & 666 & ref \\
\hline & Recs known & 296 & $1.86[1.40,2.46] \#$ & 679 & $1.71[1.35,2.17] \#$ \\
\hline \multirow[t]{3}{*}{ Modelling-pri (PA) } & 0-2 times a week & 466 & ref & - & \\
\hline & 3-4 times a week & 375 & $1.26[0.93,1.72]$ & - & \\
\hline & 5-7 times a week & 174 & $1.53[1.03,2.27]^{*}$ & - & \\
\hline \multirow[t]{3}{*}{ Modelling-sec (PA) } & 0-2 times a week & 557 & ref & - & \\
\hline & 3-4 times a week & 273 & $1.21[0.86,1.67]$ & - & \\
\hline & 5-7 times a week & 185 & $0.95[0.65,1.40]$ & - & \\
\hline Sum of items (PA) & & & $1.06[0.99,1.14]$ & - & \\
\hline \multirow[t]{2}{*}{ Modelling-pri (SB) } & Recs not met & - & & 436 & ref \\
\hline & Recs met & - & & 909 & $\begin{array}{l}1.58[1.16 \\
2.14]^{* *}\end{array}$ \\
\hline \multirow[t]{2}{*}{ Modelling-sec (SB) } & Recs not met & - & & 463 & ref \\
\hline & Recs met & - & & 882 & $1.29[0.96,1.74]$ \\
\hline No of TV at home ${ }^{d}$ & & - & & & $0.99[0.87,1.13]$ \\
\hline No of computers ${ }^{d}$ & & - & & & $0.99[0.89,1.10]$ \\
\hline No of video games ${ }^{d}$ & & - & & & $0.98[0.88,1.09]$ \\
\hline \multirow[t]{2}{*}{ TV in bedroom } & Yes & - & & 155 & Ref \\
\hline & No & - & & 1190 & $144[0.92,2.26]$ \\
\hline \multirow[t]{3}{*}{ TV left on at home } & Usually & - & & 347 & ref \\
\hline & Sometimes & - & & 716 & $1.56[1.12,2.11]^{* *}$ \\
\hline & Never & - & & 282 & $2.79[1.92,4.06] \#$ \\
\hline \multirow{3}{*}{$\begin{array}{l}\text { Rules on media equip- } \\
\text { ment usage }\end{array}$} & Not at all/ a little & - & & 260 & ref \\
\hline & Somewhat & - & & 388 & $0.76[0.53,1.07]$ \\
\hline & A lot & - & & 697 & $1.11[0.81,1.53]$ \\
\hline
\end{tabular}

${ }^{*} p<0.05 * *_{p}<0.005 \# p<0.0005 ; S D$, socio-demographic; trade, trade apprenticeship and diploma; recs, recommendations; modelling-pri, modelling of behaviour by primary caregiver; modelling-sec, modelling of behaviour by secondary caregiver; PA, physical activity; SB, sedentary behaviour

${ }^{\text {a }}$ Dichotomised into meeting National Physical Activity Guidelines of at least 3 hours/day of light activity or not

${ }^{b}$ Dichotomised into meeting National Physical Activity Guidelines of no more than 1 hour/day screen time or not

${ }^{c}$ OR- odds ratio; $95 \% \mathrm{Cl}-95 \%$ confidence intervals. OR and $95 \% \mathrm{Cl}$ calculated using Logistic regression

dentered as a continuous variable 
Citation: Anthea Magarey PhD, Eva Leslie PhD and Julie Tan BND (Hons) (2015) Relationships between Home Environment Factors and Parental Report of Diet Quality, Physical Activity and Sedentary Behaviours in 4-5 year olds: A Cross-sectional Study. F Nutr Reprt 1(1): 9-15. doi: https:// doi.org/10.24218/fnr.2015.02.

parental knowledge of the physical activity recommendations and primary caregivers' modelling of physical activity. The literature on parent modelling and children's physical activity is inconsistent. Sallis et al. [22] reviewed 54 studies in 3-12 year olds on correlates of children's physical activity and concluded that parent modelling was not significantly associated with child's physical activity, in contrast to this study. A more recent review [23] on the same age group showed that father's physical activity level had a stronger association than did mothers' while studies that did not differentiate between parents did not have significant findings. Our study found that the primary caregivers' modelling had a stronger association with child physical activity than did the secondary caregivers modelling.

The amount of outdoor play equipment was not significantly associated with children's physical activity levels. This finding is supported by previous studies [23-26]. One possible explanation for this finding is that child at this age is likely to engage in other outdoor activities that do not require play equipment such as running, catching, imaginative play and dancing. In addition it is possible for equipment to be readily available but rarely used.

Similarly, parentalknowledge of the screen time recommendations and primary caregivers' TV viewing was associated with child's screen time. However, the number of TVs, computers and video games were not associated with screen time as has been previously found in children $3-12$ years $[27,28]$. This association was consistently found in preschoolers. For example Spurrier and colleagues reported that multiple TVs were not associated with screen time in the same age group; however, the absence of a TV in the bedroom was associated with lower screen time [29]. This was consistent with the literature [30-32]. A possible explanation is, rather than the total number of media equipment present in the house, the presence of the media equipment in the area that the child spends most time e.g. living room or bedroom, contributes more to screen time. Notably, not leaving the TV on was associated with meeting guidelines for sedentary behaviour, as has been previously reported [27,32] while simply setting rules on media equipment usage was not associated with meeting guidelines. Thus turning off the TV when not in use and removing the TV from the child's bedroom may be the most useful strategies in future interventions.

The strengths of the study are the large sample size, although missing data reduced this disproportionally according to the outcome of interest, and the diversity of disadvantage due to the selection of relatively more disadvantaged communities in metropolitan and regional areas. This can provide some insights on guiding family-based obesity prevention strategies in these communities.

\section{Limitations}

A key limitation is the cross-sectional design of this study which limits the ability to make causal inferences. Additionally, there is potential for selection bias where parents who are more educated or have greater interest in nutrition are more likely to participate [33]. While the targeted communities were the more disadvantaged, within any area, there will be diversity in education and income levels. This is evident from the large number of respondents in the higher income strata (54\%) and the substantial proportion with tertiary education (38.7\%). A disproportionately small number of responses were received from indigenous people (1.1\%). Furthermore, the response rate for parents completing surveys was low at 14\% (unpublished observations, Leslie). The initial selection of disadvantaged communities and the additional low response rate within those communities raises issues of generalizability to both the whole population and to the population we intended to study.

The questionnaire used for the study was designed by a team of experts specifically to evaluate the OPAL intervention, using previously validated questionnaires as reference. However, the psychometric properties of the questionnaire used were not tested specifically so results must be interpreted with caution. We also acknowledge that there may be gaps in parents' knowledge of what children eat outside the home when not under parental supervision. Using parent reported data is ideal for this age group but parents are still susceptible to providing socially desirable responses, resulting in under or overestimation of the true associations.

\section{Conclusion}

Dieticians or public health researchers can utilise these findings and engage families in suitable activities (e.g. turning the TV off during meals, increasing parents' knowledge about dietary guidelines) as one strategy to promote healthy home environments and parental modelling of health behaviours.

This study has identified potentially modifiable variables influencing preschool children's behaviour among those from disadvantaged communities. Child activity and dietary patterns were found to be influenced by parent knowledge, modelling and encouragement in the respective directions. There were no significant associations between the number of media equipment and physical activity items in the household and children meeting activity guidelines. Further investigation on parental efficacy to support positive changes in the home environment, especially in lower SES communities, is also warranted.

\section{Acknowledgements}

We thank all families who completed questionnaires, the Flinders OPAL Evaluation Project fieldwork team for their efforts in recruitment, data collection and entry and SA Department of Health for allowing Flinders University the use of the data.

\section{Financial support}

This manuscript uses or includes information commissioned by the South Australian Department of Health to be developed and collected by Flinders University of South Australia. OPAL is a joint program of the Australian, State and Local Governments. The views expressed are solely those of the authors and do not necessarily reflect those of the South Australian Government, or any other Australian, State, Territory or Local government.

\section{Notes}

The study protocol was approved by Flinders University Social and Behavioural Research Ethics Committee and other relevant committees. 
Citation: Anthea Magarey PhD, Eva Leslie PhD and Julie Tan BND (Hons) (2015) Relationships between Home Environment Factors and Parental Report of Diet Quality, Physical Activity and Sedentary Behaviours in 4-5 year olds: A Cross-sectional Study. F Nutr Reprt 1(1): 9-15. doi: https:// doi.org/10.24218/fnr.2015.02.

\section{References}

1. World Health Organisation [Internet]. Childhood overweight and obesity. 2000. Available from: http://www.who.int/ dietphysicalactivity/childhood/en/

2. Vaska V, Volkmer R. Increasing prevalence of obesity in South Australian 4-year-olds: 1995-2002. J Paediatr Child Health. 2004; 40:353-5.

3. Wake M, Hardy P, Canterford L, Sawyer M, Carlin JB. Overweight, obesity and girth of Australian preschoolers: prevalence and socioeconomic correlates. Int J Obes(Lond). 2005; 31:1044-51.

4. Australian Institute of Health and Welfare. A rising epidemic: obesity in Australian children and adolescent. Risk Factor Monitoring, Canberra, 2004.

5. National Medical and Health Research Council. Clinical Practice Guidelines for the Management of Overweight and Obesity in Adults, Adolescents and Children in Australia. Department of Health and Aging, Canberra, 2013.

6. Swinburn B, Egger G, Raza F. Dissecting obesogenic environments: the development and application of a framework for identifying and prioritizing environmental interventions for obesity. Prev Med. 1999; 29:563-70.

7. Bell AC, Kremer PJ, Magarey AM, Swinburn BA. Contribution of 'noncore' foods and beverages to the energy intake and weight status of Australian children. Eur J Clin Nutr. 2005; 59:639-45.

8. Hardy LL, King L, Hector D, Lloyd B. Weight status and weightrelated behaviors of children commencing school. Prev Med. 2012; 55:433-7. doi: 10.1016/j.ypmed.2012.09.009.

9. Golan M. Parents as agents of change in childhood obesity--from research to practice. Int J Pediatr Obes. 2006; 1:66-76.

10. Hesketh KD, Campbell KJ. Interventions to prevent obesity in 0-5 year olds : an updated systematic review of the literature. Obesity. 2010; 18:S27-S35. doi: 10.1038/oby.2009.429.

11. Campbell K, Hesketh K. Strategies which aim to positively impact on weight, physical activity, diet and sedentary behaviours in children from zero to five years: a systematic review of the literature. Obes Rev. 2007; 8:327-38.

12. Wansink B. Nutritional gatekeepers and the $72 \%$ solution. J Am Diet Assoc. 2006; 106:1324-7.

13. Commonwealth of Australia. Move and Play Every Day - National physical activity recommendations for children 0-5 years. Department of Health, Canberra, 2014.

14. Borys JM, Le Bodo Y, Jebb SA, Seidell JC, Summerbell C, Richard D, et al. EPODE approach for childhood obesity prevention: methods, progress and international development. Obes Rev. 2012; 13:299315. doi: 10.1111/j.1467-789X.2011.00950.x.

15. Cole TJ, Bellizzi MC, Flegal KM, Dietz WH. Establishing a standard definition for child overweight and obesity worldwide: international survey. BMJ. 2000; 320:1240-3.

16. National Medical and Health Research Council. Australian Dietary Guidelines. Commonwealth Department of Health and Ageing, Canberra, 2013.

17. Golley RK, Magarey AM, Daniels LA. Children's food and activity patterns following a six-month child weight management program. Int J of Pediatr Obes. 2011; 6:409-14. doi: 10.3109/17477166.2011.605894.
18. Gehling RK, Magarey AM, Daniels LA. Food-based recommendations to reduce fat intake: An evidence-based approach to the development of a family-focused child weight management program. J Paed Child Health. 2005; 41:112-8.

19. McGowan L, Croker H, Wardle J, Cooke LJ. Environmental and individual determinants of core and non-core food and drink intake in preschool aged children in ther United Kingdom. Eur J Clin Nutr. 2012; 66:322-8. doi: 10.1038/ejcn.2011.224.

20. Campbell KJ, Crawford DA, Ball K. Family food environment and dietary behaviours likely to promote fatness in 5-6 year-old children. Int J Obes(Lond). 2006; 30:1272-80.

21. Wyse R, Campbell E, Nathan N, Wolfenden L. Associations between charactristics of the home environment and fruit and vegetable intake in preschool children: a cross sectional study. BMC Public Health. 2011; 11:938. doi:10.1186/1471-2458-11-938.

22. Sallis JF, Prochaska JJ, Taylor WC. A review of correlates of physical activity of children and adolescents. Med Sci Sports Exerc. 2000; 32:963-75.

23. Ferreira I, van der Horst K, Wendel-Vos W, Kremers S, van Lenthe FJ, Brug J. Environmental correlates of physical activity in youth - a review and update. Obes Rev. 2007; 8:129-54.

24. Maitland C, Stratton G, Foster S, Braham R, Rosenberg M. A place for play? The influence of the home physical environment on children's physical activity and sedentary behaviour. Int J Behav Nutr Phys Act. 2013; 10:99. doi: 10.1186/1479-5868-10-99.

25. van der Horst K, Oenema A, Ferreira I, Wendel-Vos W, Giskes K, van Lenthe $F$, et al. A systematic review of environmental correlates of obesity-related dietary behaviors in youth. Health Educ Res. 2007; 22:203-26.

26. Davison KK, Lawson CT. Do attributes in the physical environment influence children's physical activity? A review of the literature. Int J Behav Nutr Phys. 2006; 3:19.

27. Yalcin SS, Tugrul B, Nacar N, Tuncer M, Yurdakok K. Factors that affect television viewing time in preschool and primary schoolchildren. Pediatr Int. 2002; 44(6):622-7.

28. Marshall SJ, Biddle SJ, Gorely T, Cameron N, Murdey I. Relationships between media use, body fatness and physical activity in children and youth: a meta-analysis. Int J Obes Rel Met Disord. 2004;28(10):1238-46.

29. Spurrier NJ, Magarey AM, Golley R, Curnow F, Sawyer MG. Relationships between the home environment and physical activity and dietary patterns of preschool children: a cross-sectional study. Int J Behav Nutr Phys. 2008;5:1-12. doi: 10.1186/1479-5868-5-31.

30. De Craemer M, De Decker E, De Bourdeaudhuij I, Vereecken C, Deforche B, Manios Y, et al. Correlates of energy balance-related behaviours in preschool children: a systematic review. Obes Rev. 2012;13 Suppl 1:13-28. doi: 10.1111/j.1467-789X.2011.00941.x.

31. Christakis DA, Ebel BE, Rivara FP, Zimmerman FJ. Television, video, and computer game usage in children under 11 years of age. J Pediatr. 2004;145:652-6.

32. Carson V, Janssen I. Associations between factors within the home setting and screen time among children aged $0-5$ years: a crosssectional study. BMC Public Health. 2012;12:539. doi:10.1186/14712458-12-539.

33. Turrell G, Najman JM. Collecting food-related data from low socioeconomic groups: how adequate are our current research designs? Aust J Public Health. 1995;19:410-6. 